\title{
PerCursos
}

\section{A utopia decolonial: o projeto transmoderno, pluriversal e o direito à diferença de igualdade}

\section{Resumo}

O presente trabalho tem o objetivo de apresentar a utopia do pensamento decolonial, o projeto transmoderno e pluriversal, a partir das obras de Walter Mignolo e de Enrique Dussel. Essa proposta não está limitada ao interior da modernidade eurocêntrica e nem é simplesmente a sua negação, como propõe o pós-modernismo. A utopia decolonial, enquanto projeto de sociedade futura, é uma terceira via, que parte de um outro lugar, da exterioridade da modernidade. Sendo assim, o trabalho é dividido em duas partes. Em primeiro lugar, é realizada uma apresentação da crítica decolonial ao universalismo. Em segundo lugar, o projeto de transmodernidade é abordado. Para tanto, a metodologia utilizada é a revisão de literatura ou reconstrução categorial.

Palavras-chave: Transmodernidade. Pluriversalidade. Colonialidade. Decolonialidade. Direito à diferença.

\section{Rayann Kettuly Massahud de Carvalho}

Doutorando e Mestre em Direito pela Universidade Federal de

Minas Gerais - UFMG.

Brasil

rayannkmassahud@gmail.com

\section{Para citar este artigo:}

CARVALHO, Rayann Kettuly Massahud de. A utopia decolonial: o projeto transmoderno, pluriversal e o direito à diferença de igualdade. PerCursos, Florianópolis, v. 21, n.47, p. 130 - 152, set./dez. 2020.

DOI: $10.5965 / 1984724621472020130$

http://dx.doi.org/10.5965/1984724621472020130 


\title{
The decolonial utopia: the transmodern, pluriversal project and the right to equality difference
}

\begin{abstract}
The present work aims to present the utopia of decolonial thought, the transmodern and pluriversal project, based on Walter Mignolo and Enrique Dussel's works. This proposal is not limited to the interior of Eurocentric modernity, nor is it simply its negation, as postmodernism proposes. Decolonial utopia, as a project for a future society, is a third way, starting from another place, from the exteriority of modernity. Therefore, the work is divided into two parts. First, there is a presentation of the decolonial critique of universalism. Second, the transmodernity project is addressed. Therefore, the methodology used is the literature review or categorical reconstruction.
\end{abstract}

Keywords: Transmodernity. Pluriversality. Coloniality. Decoloniality. Right to difference. 


\section{Introdução}

O pensamento decolonial é uma corrente crítica situada na América Latina (BALLESTRIN, 2013, p. 89), organizada em torno e a partir do Grupo Modernidade/Colonialidade (GOMES; MASSAHUD DE CARVALHO, 2020, p. 3) e que tem, nos últimos anos, influenciado fortemente as ciências sociais no Brasil (BELLO, 2015, p. 50), propondo a realização de um giro decolonial (CASTRO-GOMÉZ; GROSFOGUEL, 2007, p. 09). Essa corrente é marcada pela interdisciplinaridade e pela pluralidade; não obstante a existência de divergências e de distintos diagnósticos (MASSAHUD DE CARVALHO, 2020, p. 17-18), há um fio condutor que conecta os seus e as suas integrantes, permitindo a constituição e a consolidação do pensamento decolonial como um campo próprio (MASSAHUD DE CARVALHO, 2020, p. 104).

Entre os seus pressupostos cabe destacar, primeiramente, o deslocamento do início da modernidade do século XVII e XVIII (DUSSEL, 2005, p. 27) para o final do século XV, a partir da experiência colonial na América (DUSSEL, 2007, p. 11). Em segundo lugar, a compreensão de que a modernidade possui uma face oculta e violenta, a colonialidade (QUIJANO, 2000, p. 343). Em terceiro, uma crítica ao eurocentrismo da modernidade e da pós-modernidade (DUSSEL, 2015a, p. 283; MIGNOLO, 2010, p. 14-15; QUIJANO, 2010, p. 8485), propondo um projeto outro de sociedade futura, nesse sentido uma utopia, que não é moderna ou pós-moderna (MIGNOLO, 2017b, p. 19), denominada como transmodernidade (DUSSEL, 2000, p. 50-51). O projeto transmoderno é um projeto global pluriversal (MIGNOLO, 2003, p. 418), que rompe com as hierarquias tipicamente modernas (QUIJANO, 2009a, p. 04) e que se ancora na realização do direito à diferença de igualdade (MIGNOLO, 2015b, p. 357).

O objetivo do presente artigo é apresentar o supracitado projeto do pensamento decolonial. Nesse quadro, o trabalho será organizado em duas partes. Em um primeiro momento apresentar-se-á uma crítica à perspectiva universalista a partir de Walter Mignolo e a sua proposta de diversalidade como projeto global - buscando realizar o direito à diferença de igualdade. Em seguida será exposta a formulação mais robusta da utopia decolonial, o projeto transmoderno de Enrique Dussel. 
A utilização dos supracitados autores, Enrique Dussel e Walter Mignolo, justifica-se pois são duas das três bases teórico-conceituais em que se assenta o pensamento decolonial (BELLO, 2015, p. 51; BERCLAZ, 2017, p. 205-206; BRAGATO; CASTILHO, 2014, p. 19; PAZELLO, 2014 p. 39). ${ }^{1}$ No mesmo sentido, essa escolha pelos dois autores, bem como a não utilização de Aníbal Quijano, justifica-se pois são eles, dentre os três, que trabalharam de um modo mais detido e sistematizado a questão em tela: a utopia decolonial, o projeto de uma sociedade futura.

Enrique Dussel e Walter Mignolo são membros do Grupo Modernidade/Colonialidade. Esse, foi membro do Grupo Latino-americano de Estudos Subalternos (BALLESTRIN, 2013, p. 95), atualmente é professor na Universidade de Duke, e entres as suas obras destinadas a refletir criticamente sobre as margens internas e externas da modernidade, sobre as múltiplas formas de saber e de experiências sociais, de memórias, e culturas que coexistem no mundo, cabe destacar os livros: Histórias Locais/Projetos Globais (2000) e A Ideia de América Latina (2005). Aquele, por sua vez, é uma dos principais autores da Filosofia da Libertação. Enrique Dussel possui uma vasta obra, produzida em espiral; em cada camada, o autor se debruça sobre e a partir de um campo - entre eles: Teologia, Filosofia, História, Ética, Política, Econômica Política buscando refletir sobre a condição latino-americana - situada em um mundo moderno/colonial e capitalista.

Por fim, cabe destacar que o caminho metodológico utilizado é a revisão de literatura ou reconstrução categorial.

\section{Para uma alternativa ao universalismo como totalidade: a pluriversalidade como projeto global}

Este tópico é destinado a apresentar a crítica de Walter Mignolo à perspectiva universalista. Para tanto, será utilizado, em maior medida, o Livro Histórias Locais/Projetos Globais (2003) e o artigo, intitulado: desafios decoloniais hoje (2017) -

\footnotetext{
${ }^{1}$ A terceira é a obra do sociólogo peruano Aníbal Quijano.
} 
ainda que cotejados por outros textos do mesmo autor. Não obstante a sua crítica a um universalismo totalizante e homogeneizador aparecer de modo transversal em sua obra, nesses textos o autor se debruça de modo mais verticalizado na referida temática, por isso, justifica-se a utilização deles.

Segundo W. Mignolo, a modernidade se apresenta como um projeto global, no entanto ela desconsidera a pluralidade infinita de histórias locais que coexistem, bem como o próprio fato desses projetos globais serem também situados em uma determinada região e em um dado período de tempo (MIGNOLO, 2003, p. 287).

Essas pretensões universais e totalizantes são em si violentas, pois acabam negando as diversas formas de experiência social, diferentes realidades, histórias, memórias, culturas, tradições e saberes que existem concomitantemente no mundo e, igualmente, desconsiderando a existência da diferença colonial e da colonialidade (MIGNOLO, 2017b, p. 29). É necessário, portanto, reconhecer essa presença plúrima, bem como dar voz àquelas e àqueles que foram e, em grande medida, continuam sendo silenciados e silenciadas, resgatando, assim, suas histórias locais (MIGNOLO, 2017b, p. 29) — parte dos propósitos que guiam o movimento decolonial (MIGNOLO, 2003, p. 158).

Contudo, mesmo reconhecendo que essas teorias totalizantes e universais são, em alguma medida, violentas, não há uma negação absoluta delas (MIGNOLO, 2003, p. 241242). A posição assumida por W. Mignolo parece ser de desvelar que elas não são suficientes para explicar todas as realidades, bem como para solucionar dilemas, mazelas e opressões existentes e que são enfrentados nos distintos espaços-tempos (MIGNOLO, 2003, p. 262). Ou melhor, em vez de negá-las ou de decretar sua inutilidade, busca-se evidenciar que há insuficiências nas teses, de pretensões universais, produzidas em determinados contextos para explicar outras localidades e em diferentes tempos históricos. Pois seus contributos, como de todas as outras teorizações, partem também da análise de uma forma de existência específica (MIGNOLO, 2003, p. 127-128).

Cabe ressaltar que essas especificidades até podem se manifestar em outras regiões, mas não necessariamente uma teoria específica consegue explicar da mesma forma as distintas situações que ocorrem em localidades diferentes (MIGNOLO, 2003, p. 
127-128). Um bom exemplo é o caso da psicanálise freudiana - tal como relida por F. Fanon:

\begin{abstract}
Certamente Fanon não está negando a contribuição de Freud, mas apenas demarcando seu limite para além dos distúrbios psicológicos, de uma certa classe social de um setor específico da Europa Ocidental no final do século 19 numa sociedade de tipo cristão e vitoriano. É inegável que esse tipo de estrutura social de distúrbio psicológico poderia manifestar-se em outras partes do planeta, particularmente para onde se tenha transplantado a sociedade europeia sem muita interferência da população 'nativa'. [...] Uma vez mais, não são as contribuições de Freud que estão sendo questionadas, mas os limites de sua utilidade evidenciados pela revelação da diferença colonial. (MIGNOLO, 2003, p. 127-128)
\end{abstract}

Essa crítica é igualmente feita a outros autores, autoras e teorias, entre elas a tradição marxista. Segundo W. Mignolo:

O marxismo não nos oferece as ferramentas para poder pensar (n)a exterioridade. O marxismo é uma invenção europeia que surgiu para enfrentar, no seio da própria Europa, tanto a teologia cristã como a economia liberal, ou seja, o capitalismo. O marxismo resulta limitado tanto nas colônias como no mundo não-moderno em geral, porque se mantém dentro da matriz colonial do poder que cria exterioridades no espaço e no tempo (bárbaros, primitivos e subdesenvolvidos). (MIGNOLO, 2017b, p. 29)

No mesmo sentido, o autor afirma que: "a diferença colonial não foi ainda percebida por intelectuais marxistas críticos" (MIGNOLO, 2003, p. 250). Essa mesma crítica é direcionada não apenas à tradição, mas também ao próprio Karl Marx, pois, segundo W. Mignolo - mesmo reconhecendo a contribuição do autor para analisar e compreender o funcionamento do modo de produção capitalista -, Karl Marx permaneceria trabalhando em termos de totalidade, não tendo "consciência da alteridade, da exterioridade do sistema". Por isso, o seu pensamento ainda permaneceria situado "dentro da epistemologia moderna" (MIGNOLO, 2003, p. 245). No mesmo sentido, W. Mignolo entende que "o colonialismo e o racismo não foram elementos 
cruciais da análise do capitalismo feita por Marx" (MIGNOLO, 2003, p. 198), assim, "a experiência colonial permaneceu invisível para Marx" (MIGNOLO, 2017b, p. 16).

Portanto, não se trata de negar essas teorias, mas de reconhecer suas limitações. Exatamente por isso, elas podem continuar sendo utilizadas, desde que sua leitura e seus usos não sejam realizados de maneira não refletida (MIGNOLO, 2003, p. 241). Ou seja, devem ser sempre mediadas e adequadas, dentro das possibilidades, à própria realidade. Para além disso, deve-se sempre partir da compreensão de que, mesmo sendo apresentadas como universais, elas são também interessadas, localizadas e balizadas por histórias locais.

Dessa forma, para uma "alternativa para o universalismo" presente nas teorias modernas (MIGNOLO, 2003, p. 418), é necessária a construção de uma nova opção, uma nova forma de pensar. Ela precisa ser capaz de romper com as cronologias estabelecidas pelo paradigma moderno e pós-moderno, bem como pela ciência eurocêntrica (MIGNOLO, 2017a, p. 15).

A proposta de uma alternativa ao universalismo, então, não é um novo universal que se sobrepõe ao universal anterior, sob o risco de permanecer dentro do paradigma moderno (MIGNOLO, 2017a, p. 15). Nele, a totalidade passa a ser compreendida não como homogênea, mas como heterogeneidade múltipla, "uma fragmentação" de histórias locais (MIGNOLO, 2003, p. 292). Nessa totalidade como heterogeneidade não há um "líder único" (MIGNOLO, 2017a, p. 14), bem como não existe uma única lógica que controle todas as outras (MIGNOLO, 2003, p. 290).

A partir dessa lente, é necessário analisar a América Latina, bem como todas as identidades geo-históricas apresentadas como homogêneas. Por exemplo: a Europa, o Oriente e o Ocidente não são um todo uniforme, mas devem ser compreendidos em sua complexidade, ou seja, é preciso assumir a sua heterogeneidade (MIGNOLO, 2003, p. 238). Em verdade, todas essas áreas são compostas por um mosaico de histórias locais que coexistem.

Esse caminho já foi apontado por A. Quijano e vai na direção oposta à universalidade como totalidade única, expressando-se em um "conceito não totalitário de 
totalidade", uma totalidade que coexista com as outras, em uma "pluriversalidade" (MIGNOLO, 2010, p. 16). Referida pluriversalidade é apresentada por E. Dussel como o projeto da "transmodernidade" (MIGNOLO, 2010, p. 16). Busca-se, assim, a constituição de um projeto "pluriversal em vez de universal” (MIGNOLO, 2017a, p. 14) ou, em outros termos, que propõe a "diversalidade como projeto universal" (MIGNOLO, 2003, p. 418). ${ }^{2}$

Nas palavras do próprio autor:

Devemos esclarecer: a pluriversalidade não é a rejeição de reivindicações universais, mas a rejeição da universalidade entendida como um universal abstrato ancorado em uma monológica. Um princípio universal baseado na ideia do diverso não é uma contradição de termos, mas um deslocamento de estruturas conceituais. Segundo Hinkelammert, os zapatistas reivindicam a diversidade como um projeto universal: "um mundo onde muitos mundos se encaixam", o direito à diferença de igualdade, o "mandar obedecendo". Em um mundo como esse, composto por múltiplos mundos, não são necessários universais abstratos ou significantes vazios, mas conectores que ligam a revolução teórica e suas consequências éticas a projetos semelhantes ao redor do globo, emergindo desde a diferença colonial. (MIGNOLO, 2015b, p. 357)

A partir desse projeto de pluriversalidade, que reconhece a totalidade como heterogeneidade (MIGNOLO, 2017b, p. 28), os diferentes projetos que são hodiernamente narrados como "opções rivais" não mais buscam se sobrepor uns aos outros, bem como não há hierarquização entre eles. A partir da pluriversalidade, eles passam a conviver e se aceitar reciprocamente, abandonando a percepção tipicamente moderna de que há apenas uma única opção disponível (MIGNOLO, 2017a, p. 14).

Assim, reaparece a possibilidade da construção de um futuro global, mas a partir de uma outra perspectiva. No tempo presente, no entanto, estão emergindo três

\footnotetext{
${ }^{2}$ A partir disso, assim como a totalidade não é negada plenamente, da mesma forma não há uma negação de todas as metanarrativas. Segundo W. Mignolo: trata-se de "[...] uma estratégia crucial para a construção de macronarrativas na perspectiva da colonialidade. Como tais, essas macronarrativas não estão predestinadas a enunciar a verdade que os discursos coloniais não contaram. [...] Na perspectiva da colonialidade, as macronarrativas são precisamente os lugares nos quais 'um outro pensamento' poderia ser implementado, não para dizer a verdade em oposição às mentiras, mas para pensar de outra maneira, caminhar para 'uma outra lógica' - em suma, para mudar os termos, e não apenas o contexto de conversação. Essas narrativas propiciam pensar a colonialidade, e não apenas a modernidade, de forma livre" (MIGNOLO, 2003, p. 106).
} 
possibilidades disputando a criação de um futuro global, sendo elas: a "reocidentalização mediante a continuidade do projeto incompleto da modernidade ocidental", a "desocidentalização dentro dos limites da modernidade ocidental" e a "decolonialidade no surgimento de uma sociedade política global que desprende da reocidentalização e da desocidentalização" (MIGNOLO, 2017b, p. 28). Acerca da terceira via, verifica-se que

[...] a opção decolonial pelo momento não é uma opção estatal. É uma opção da sociedade política global. A sociedade política global está constituída não por milhares, mas por milhões de pessoas que se agrupam em projetos para ressurgir, re-emergir e re-existir. Isto já é não só resistir, porque resistir significa que as regras do jogo são controladas por alguém a quem resistimos. Os desafios do presente e do futuro consistem em poder imaginar e construir uma vez que nos liberamos da matriz colonial de poder e nos lançamos ao vazio criador da vida plena e harmônica. (MIGNOLO, 2017b, p. 31)

Nesse projeto de um futuro global, assentado na "pluriversalidade como um projeto universal” (MIGNOLO, 2017a, p. 14), a sua constituição é realizada por meio da sociedade política global (MIGNOLO, 2017b, p. 28), que reconhece a complexidade da realidade e a totalidade como sendo plural. Nela, os diferentes "povos e comunidades" não precisam alcançar um determinado modelo ideal previamente imposto, "eles têm direito de ser diferentes precisamente porque 'nós' somos todos iguais em uma ordem universal metafísica, embora sejamos diferentes no que diz respeito à ordem global da colonialidade do poder” (MIGNOLO, 2003, p. 420. Destaque do original).

Dessa forma, uma das bases em que se ancora a sociedade política global e a pluriversalidade é o "direito de existir para coexistir com as opções existentes" (MIGNOLO, 2015c, p. 82). É necessário, então, “que nos coloquemos, enquanto pessoas, Estados, instituições, no lugar onde nenhum ser humano tem o direito de dominar e se impor a outro ser humano. É simples assim, e tão difícil” (MIGNOLO, 2017a, p. 14). A partir de então, nenhuma parcela da sociedade terá domínio nem a suposta autoridade para se impor a outros sujeitos e para prescrever o seu modelo de sociedade para outras localidades. Em seu lugar, será constituída "uma democracia compartilhada por todos os 
povos do mundo que buscam equidade e justiça social”, em oposição às constantes “injustiças e desigualdades” da modernidade/colonialidade (MIGNOLO, 2015b, p. 355).

Com a pluriversalidade e a emergência de uma sociedade política global, assentada no direito de ser diferente, as especificidades deixam de ser compreendidas e vivenciadas como hierarquias, possibilitando a construção de um futuro

[...] em direção a um mundo não-injusto, onde nenhum ser humano tem o direito ou a possibilidade de explorar ou manipular, nem a necessidade de se acreditar melhor ou superior a outro para justificar sua vida, [...] trabalhando para a descolonização do conhecimento e da subjetividade, onde surgirão ordens políticas, constitucionais e econômicas que não respondem mais aos desejos de êxitos (sejam capitalistas ou revolucionários, mas na mesma ordem de sucesso), mas aos desejos e esforços para construir um multiverso, [...] um mundo onde se encaixam muitos mundos. (MIGNOLO, 2008, p. 331-332)

Para caminhar nesse sentido, porém, a única possibilidade é "pensar e agir descolonialmente" (MIGNOLO, 2017a, p. 14), isto é, é preciso transformar radicalmente os próprios termos da conversação “e não apenas o conteúdo" (MIGNOLO, 2017a, p. 14). Serão necessários, assim, novos "princípios epistemológicos" capazes de rearticular a diferença colonial (MIGNOLO, 2003, p. 420).

\section{Um caminho outro: rumo à Transmodernidade}

Para a realização da exposição sobre o projeto transmoderno, de Enrique Dussel, serão utilizados, em grande medida, artigos compilados no Livro, publicado em 2015, intitulado Filosofias do Sul, em que o autor apresenta de modo mais bem acabado o que consiste a transmodernidade, o projeto de uma sociedade futura outra, a utopia decolonial.

Na concepção dominante não se compreende, em regra, que haja diferentes modernidades que coexistem. O entendimento hegemônico é o de que há apenas uma modernidade, a modernidade europeia, que é replicada e copiada "no processo de 
globalização em outras regiões do mundo". No limite, compreende-se, assim, que é a mesma modernidade sendo implantada de formas diferentes em lugares diferentes. "É a mesma modernidade, imitada e expandida em certos aspectos" (DUSSEL, 2012, p. 29).

Em face disso, a proposta de E. Dussel é a realização de uma crítica à concepção e às narrativas da modernidade, que tem como ponto de partida um lugar outro e não o interior da modernidade. Isto é, a crítica está situada no exterior da modernidade eurocêntrica; ela não se limita a uma única região (a Europa). Ela assume uma outra perspectiva, comprometida com o que há além dessa região, "ou seja, global (não provinciana, como eram as perspectivas europeias)" (DUSSEL, 2015b, p. 57).

Sendo assim, não há uma vinculação à tradição moderna hegemônica, da mesma forma como não há à corrente pós-moderna, pois são ambas eurocêntricas (DUSSEL, 2015a, p. 283): elas permanecem como uma "visão europeia da Modernidade" (DUSSEL, 2015b, p. 56). Em verdade, o

[...] "pós" da Pós-modernidade não Ihe tira seu eurocentrismo; pressupõe como óbvio que a Humanidade futura alcançará as mesmas características de "situação cultural" que a Europa ou os Estados Unidos pós-modernos, à medida que se "modernizam" pelo processo de "globalização" já iniciado, irreversível e inevitável. Sob o signo dessa "inevitabilidade" modernizadora, a Pós-modernidade é profundamente eurocêntrica, visto que não pode nem imaginar que as culturas excluídas em sua positividade pelo processo moderno colonial (desde 1492) e ilustrado (desde 1789) [...] possam contribuir "positivamente" na construção de uma sociedade e cultura futura, posterior à cultura Moderna europeia e norte-americana, mais além do seu "último momento", de sua crise atual, do seu limite (mais além do momento "Pós"-moderno da Modernidade). É necessário pensar a questão mais radicalmente. (DUSSEL, 2016, p. 166)

Busca-se, assim, a realização de um projeto distinto da modernidade e da pósmodernidade, uma via alternativa, denominada como transmodernidade (DUSSEL, 2000, p. 50-51).

O primeiro passo para a realização desse projeto é questionar a visão hegemônica sobre as culturas em geral e, mais especificamente, sobre o modo com que a cultura 
europeia é narrada como a única realmente moderna, superior, que se expande por todo o planeta (DUSSEL, 2015b, p. 56). Para isso, é necessário abandonar as lentes limitadas do eurocentrismo e aumentar o campo de visão para perceber que há uma infinidade de culturas que coexistem com a sociedade e a cultura europeia hegemônica. Elas foram negadas, foram retratadas pela europeia como bárbaras, como não culturas, como inferiores e sem história. Ao se reconhecer essa diversidade de culturas no mundo, está presente a possibilidade de realização da crítica à modernidade, bem como uma alternativa, um caminho rumo ao projeto transmoderno (DUSSEL, 2015a, p. 282-283).

É necessário compreender que coexistem, em permanente tensão, com a cultura moderna eurocêntrica, outras culturas (DUSSEL, 2015b, p. 57). Isso porque a visão míope, pobre e distorcida sobre as culturas periféricas teve como desdobramento a compreensão inadequada sobre a própria cultura europeia (DUSSEL, 2015b, p. 56). Há no mundo não apenas uma única cultura moderna que se expande: há uma diversidade delas, que sobreviveram e são a expressão de uma constelação de alteridades culturais (DUSSEL, 2015a, p. 282-283).

Cabe ressaltar que essas culturas que coexistem com a cultura moderna europeia são "pré-modernas", mas não inferiores. Elas são pré-modernas no sentido de que são anteriores, elas já existiam antes da Europa se constituir como Europa moderna, antes da inauguração da própria modernidade, do desenvolvimento do capitalismo e da constituição de um sistema-mundo. Ao mesmo tempo, apesar de anteriores, elas são simultâneas, elas sempre coexistiram e continuam coexistindo na modernidade (DUSSEL, 2015b, p. 63).

Não há uma crença ingênua de que essas culturas negadas e silenciadas são fixas e inalteradas. Elas tiveram contato com a modernidade e nesse contato se modificaram. Isto é, as culturas encobertas, que formam uma exterioridade cultural em relação à cultura moderna eurocêntrica, não são "identidades" imutáveis que sobreviveram intocadas ao longo dos anos. Elas convivem com a cultura moderna eurocêntrica e por isso foram afetadas (DUSSEL, 2015b, p. 62). São culturas que permanecem vivas e se desenvolvendo, são não modernas, uma vez que não se constituíram no interior da 
modernidade eurocêntrica. Ao mesmo tempo, são pré-modernas, pois são cronologicamente anteriores (DUSSEL, 2015b, p. 62-63).

O contato entre as diferentes culturas é constante e não necessariamente pacífico. As diferentes culturas "se enfrentam em todos os níveis da vida cotidiana: a comunicação, a educação, a pesquisa, a política de expansão ou de resistência cultural ou mesmo militar" (DUSSEL, 2015b, p. 57). Portanto, no contato com a modernidade europeia, essas culturas foram colonizadas em alguma medida. Ao mesmo tempo, a maior parte de seus valores e estruturas foi desprezada pela modernidade e por suas próprias elites locais (DUSSEL, 2015b, p. 62).

Apesar disso, há ainda muito delas que permanece vivo. Pois a dominação e a imposição da cultura europeia é algo muito recente na história. A Europa veio "a ser o 'centro' do mercado mundial” há apenas dois séculos (DUSSEL, 2016, p. 169), mais especificamente após a Revolução Industrial. Trata-se, então, de um período relativamente pequeno para que a Europa tenha conseguido "transformar com profundidade" as culturas de impérios milenares, como "a chinesa", "a hinduísta, a islâmica, a bizantino-russa, e até mesmo a bantu ou as da América Latina (de diferente composição estrutural)" (DUSSEL, 2015b, p. 62).

Essas culturas foram, em parte, colonizadas, mas a maior parte de suas estruturas de valores foram sobretudo excluídas, desprezadas, negadas, ignoradas mais do que aniquiladas. O sistema econômico e político foi dominado no exercício do poder colonial e da acumulação gigantesca de riqueza, mas essas culturas têm sido interpretadas como desprezíveis, insignificantes, sem importância e inúteis. Esse desprezo, no entanto, permitiu-lhes sobreviver em silêncio, desdenhadas simultaneamente por suas próprias elites modernizadas e ocidentalizadas. Essa alteridade negada, sempre existente e latente, indica a existência de uma riqueza cultural insuspeita, que renasce lentamente como chamas de carvão enterrado no mar de cinzas centenárias do colonialismo. (DUSSEL, 2015b, p. 62)

É importante ressaltar, contudo, que nesses contatos entre as culturas não é possível garantir que elas continuarão existindo, pois permanecem se modificando 
mutuamente no transcurso do tempo. Em outros termos: "sistemas culturais, cunhados por milênios, podem quebrar em décadas, ou se desenvolver pelo choque com outras culturas. Nenhuma cultura tem assegurada a sobrevivência de antemão" (DUSSEL, 2015b, p. 57).

Como quer que seja, apesar de a modernidade eurocêntrica se auto-compreender como a única cultura legítima, as outras culturas que foram silenciadas, invisibilizadas, desconsideradas e negadas continuam existindo, mesmo que como partes exteriores dessa modernidade. Dessa forma, após o reconhecimento dessa constelação cultural, deve-se buscar a realização de um diálogo simétrico entre elas - isto é, sem qualquer hierarquia ou pressuposto de superioridade. Pois, como estão situadas em outros lugares, podem contribuir para a realização de uma reflexão capaz de encontrar novas soluções para as mazelas do tempo presente (DUSSEL, 2015b, p. 51).

Dessa maneira, o projeto de superação da modernidade é diferente da proposta da sua superação pela renúncia, como a do pensamento pós-moderno. O projeto de transmodernidade não recusa simplesmente a modernidade: seu ponto de partida é a alteridade negada e, apesar de assumir os desafios da modernidade, responde a eles de um outro lugar, da sua própria realidade, das suas experiências sociais e culturais múltiplas (DUSSEL, 2015a, p. 283). Em verdade, a possibilidade de encontrar novas respostas para os problemas enfrentados parece estar nas experiências das culturas que foram inferiorizadas (DUSSEL, 2015b, p. 53).

Sendo assim, apesar da modernidade ter nascido em 1492, com a invasão das Américas, a sua "real superação" está relacionada com "a subsunção de seu caráter emancipador racional europeu transcendido como projeto mundial de libertação de sua Alteridade negada: a Trans-Modernidade (como novo projeto de libertação político, econômico, ecológico, erótico, pedagógico, [...]” (DUSSEL, 2000, p. 50-51). Isto é, a

[...] metacategoria de "Exterioridade" pode iluminar a análise que que se propõe indagar a "positividade" cultural não incluída pela Modernidade, não a partir das pressuposições de uma Pós-modernidade, mas sim do que temos chamado de "Trans"-modernidade. Ou seja, trata-se de um processo que parte, que se origina, que se mobiliza a partir de "outro" 
lugar [...] além da Modernidade europeia e norte-americana. A partir da "Exterioridade" negada e excluída pela expansão moderna da Europa hegemônica "existem" culturas atuais que são anteriores, que se desenvolveram junto à Modernidade europeia, que sobreviveram até o presente e que têm, portanto, um potencial de humanidade suficiente para fazer contribuições significativas na construção de uma Cultura humana futura posterior ao término da Modernidade e capitalismo. (DUSSEL, 2016, 167-168)

Para a realização desse projeto de libertação da Alteridade negada, porém, não basta apenas o reconhecimento da sua existência (DUSSEL, 2015a, p. 283). Da mesma forma, não é suficiente a ideia ingênua da possibilidade da realização de um diálogo entre as diferentes culturas como sendo algo fácil, pressupondo de antemão uma simetria entre elas que não existe (DUSSEL, 2015b, p. 57). É necessário, como passo inicial, reconhecer que as assimetrias entre as diferentes culturas existem. Para além disso, compreender que elas são decorrentes da sua história de enfrentamentos, ligada às posições que as diferentes culturas ocupavam no sistema colonial, lugares esses impostos pela cultura eurocêntrica (DUSSEL, 2015b, p. 59)

A partir da constituição de uma cultura europeia como moderna e central, as demais culturas periféricas foram consideradas como inferiores, "como mais primitivas, como pré-modernas, tradicionais e subdesenvolvidas" (DUSSEL, 2015b, p. 59). Elas sofrem com uma relação de "exploração, conflito e aniquilação" (DUSSEL, 2015b, p. 52).

Para além da relação assimétrica entre as culturas, cabe ressaltar que as elites intelectuais nos países periféricos, educadas pelos centros, contribuem para essa relação desigual e destrutiva, uma vez que elas reproduzem nas suas regiões o que aprenderam na Europa e assim se distanciam da suas culturas, dos saberes e das memórias dos seus povos, ao mesmo tempo em que se aproximam dos europeus. Assim, enquanto no centro havia uma cultura que buscava impor-se e dominar todas as outras, na periferia, por sua vez, havia uma separação abissal entre as elites locais e o restante da população (DUSSEL, 2015b, p. 52-53).

Entretanto, coexistindo com essas elites havia, na periferia, a maior parte da população. Essa maioria permanecia ligada às suas culturas ancestrais e às suas tradições, 
defendendo-se "contra a imposição de uma cultura técnica e economicamente capitalista" (DUSSEL, 2015b, p. 52-53). Desse modo, para além de um diálogo simétrico entre as culturas, que leve em consideração as suas diferenças, é necessário também a constituição de uma nova classe intelectual que não esteja engajada com os interesses da modernidade europeia, mas que sejam fiéis aos interesses do "bloco social dos oprimidos" (DUSSEL, 2015b, p. 53). É preciso a realização de um processo de longo prazo, que se ancore em diálogos interculturais e transversais, que levem sempre em consideração as assimetrias e as singularidades que existem entre as diferentes culturas (DUSSEL, 2015a, p. 283), levando a sério a pluralidade e complexidade da modernidade.

O projeto transmoderno emerge, então, do "esgotamento das premissas da modernidade"; o presente é compreendido como uma "ante-sala de uma nova Época da história". Esse novo momento não é pós-moderno, uma vez que este olhar é eurocêntrico e limitado, mas trata-se de uma "mudança radical no próprio fundamento cultural do ethos moderno", denominado como “trans-modernidade”(DUSSEL, 2012, p. 29-30).

$\mathrm{Na}$ transmodernidade rompe-se com os "pressupostos da modernidade, do capitalismo, do eurocentrismo e do colonialismo. Uma nova Época na qual as exigências da existência da vida na Terra terão exigido mudar a atitude ontológica ante a existência da natureza, do trabalho, da propriedade, das outras culturas" (DUSSEL, 2012, p. 29-30). Na transmodernidade, há uma outra "relação humanidade-natureza", que passa a ser guiada por princípios “ecológicos”, enquanto as relações humanidade-humanidade, por sua vez, são ancoradas na "solidariedade" (DUSSEL, 2016, 169). Consequentemente, as relações econômicas capitalistas serão superadas, devido às exigências naturais e "da vida da maioria da população da Terra". Ao mesmo tempo, o modelo de democracia será participativo - indo além da representação do modelo liberal —, o que impedirá a exploração, exclusão e a subalternização dos e das mais vulneráveis (DUSSEL, 2012, p. 30).

Da mesma forma, não haverá uma universalidade excludente e provinciana de uma única cultura imposta e supostamente imitada por todas as outras - que exclui e desconsidera uma variedade incontável de experiências sociais —, levando à constituição de uma identidade artificial unitária e homogênea por meio da exclusão das diferenças 
(DUSSEL, 2012, p. 30). A transmodernidade é "polifacética, híbrida, pós-colonial, pluralista, tolerante, democrática [...] e afirmativa de Identidades heterogêneas" (DUSSEL, 2016, p. 170). Ela corresponde, portanto, à constituição de algo realmente universal, que abarca as culturas anteriores ao surgimento da própria modernidade, que abarca tudo o que está além da modernidade eurocêntrica (isto é, o que a modernidade eurocêntrica considerou como inferior ou mesmo que produziu como inexistente DUSSEL, 2015b, p. 63).

A possibilidade da criação da transmodernidade não se encontra, pois, na modernidade eurocêntrica, mas na sua exterioridade. Ou melhor, se encontra na “fronteira”. Uma vez que a externalidade da modernidade "não é pura negatividade. É uma positividade de uma tradição distinta da tradição moderna. Sua afirmação é novidade, desafio e inclusão do melhor da própria modernidade” (DUSSEL, 2015b, p. 70). Nela, as culturas universais que coexistem e se desenvolvem com a modernidade, a sua alteridade, vão fornecer um ferramental para resolver os dilemas modernos, partindo de um outro lugar, das próprias culturas e experiências silenciadas e negadas (DUSSEL, 2015b, p. 63). Portanto, o projeto da Transmodernidade parte de experiências diferentes das europeias e, por isso, guarda em si a possibilidade de encontrar novos caminhos e novas perspectivas para as questões postas pela modernidade e para as que ela própria já não consegue encontrar respostas (DUSSEL, 2015a, p. 283). As novas saídas não virão do interior da modernidade eurocêntrica, elas somente vão emergir do seu exterior.

É preciso reconhecer a existência das diferentes realidades, formas de sociabilidade, imaginários, experiências sociais que, apesar de silenciadas, sempre estiveram presentes, coexistindo com a modernidade eurocêntrica e compondo os nódulos da trama multifacetada e plúrima que é a modernidade. Ou melhor, a partir desse reconhecimento e com o fim das hierarquias, caminha-se rumo ao projeto de transmodernidade.

Em síntese, a transmodernidade engloba as culturas que constituem a alteridade da modernidade e o que há de melhor produzido na modernidade. Isso não deve levar a um universalismo vazio, a uma "unidade globalizada". Pelo contrário, possibilita caminhar em direção a um pluriverso (DUSSEL, 2015b, p. 70). Essas culturas vão dialogar "com base 
na 'semelhança' comum, recriando continuamente sua própria 'distinção' analógica, transformando-se num espaço dialógico, mutuamente criativo" (DUSSEL, 2012, p. 30).

Seria razoável, então, questionar: a transmodernidade é uma utopia? Sim e não (DUSSEL, 2015b, p 70). “Trata-se de um prognóstico razoável, empiricamente argumentável, que traça um horizonte que ao menos pretenderá a superação das dominações substanciais detectadas no presente" (DUSSEL, 2012, p. 30). Trata-se do "caminho de uma utopia transmoderna" (DUSSEL, 2015b, p 70).

\section{Considerações finais}

A utopia decolonial não é moderna e nem pós-moderna, ela é uma alternativa outra, uma terceira via, é um projeto universal não totalitário, pluriversal e transmoderno. Diferentemente da tradição pós-moderna, que nega a modernidade in totum — toda e qualquer forma de universalidade, de projeto global e a razão moderna —, o pensamento decolonial contribui para o desvelamento da violência encoberta e oculta da modernidade e realiza uma crítica a essa face, a colonialidade.

Da mesma forma, propõe o alargamento sobre a compreensão do que é razão, o reconhecimento da coexistência de racionalidades outras, para além da razão prática e da razão instrumental, buscando a realização do reacoplamento entre razão e libertação que se perdeu no transcorrer da modernidade.

O pensamento decolonial defende a urgência de se resgatar as promessas modernas de uma sociedade mais livre e igualitária — inscritas nas constituições modernas - , pois a liberdade e a igualdade são pretensões sociais que se tornaram legítimas na modernidade, mas que coexistem, em aparente contradição, com a desigualdade igualmente moderna da colonialidade e do capitalismo.

Sendo assim, para a realização da utopia decolonial, é necessário usar o que há de melhor da modernidade. Entretanto, como a modernidade tem se mostrado incapaz de fornecer as respostas para as referidas promessas - ao mesmo tempo em que produz incontáveis mazelas ao tentar realizá-las -, as respostas precisam ser buscadas em 
outros lugares. Por isso, é necessário recuperar também as múltiplas formas de experiência social e os distintos projetos de sociedades futuras que foram invisibilizados, silenciados e desconsiderados, que se encontram na exterioridade da modernidade eurocêntrica, mas que, ainda que negados e encobertos, permanecem existindo.

Levando a sério toda essa complexidade do tempo presente, será possível colocar fim nas hierarquias modernas que negam a condição de humanidade de uma parcela da sociedade - dividindo as pessoas em mais e menos humanas -, que declaram a inferioridade de diversas culturas e ao afirmar que só há uma forma de conhecimento válido, a ciência, acabam por excluir diferentes saberes da condição de conhecimento. Em outros termos, será possível recuperar a multiplicidade de experiência social produzida ativamente como inexistente pela e na modernidade eurocêntrica.

Essa utopia, no entanto, não deve ser entendida apenas como um futuro distante, um dever ser, como algo que algum dia virá e será concretizado. Esse projeto, em verdade, já existe hoje, aqui e agora, pois sempre houve resistência da própria sociedade à colonialidade e, assim, já há vestígios, mesmo que ainda de modo incipiente, de uma forma de organização outra - não mais pautada na incessante busca pelo lucro e pelo valor. Pois, como ensinou Aníbal Quijano: a utopia decolonial já está em curso, "estamos começando a conviver com o futuro" e ele é organizado por aqueles e por aquelas que foram colonizados e colonizadas e que ainda são subalternizados e subalternizadas. A utopia decolonial é “outro horizonte de sentido histórico” que “já está aqui” (QUIJANO, 2009b, p. 05).

A partir da exposição do que consiste a utopia decolonial, enquanto projeto de sociedade futura, algumas questões e questionamentos emergem: será que não há uma certa ingenuidade desses autores ao acreditar em uma forma outra de sociedade, plural, multifacetada e heterogênea? Se não, não falta ainda explicar o modo com que essa transformação social radical ocorrerá? Pois, se referido momento não for explicitado de forma adequada, não há um desacoplamento, um hiato, entre o momento atual e o projeto de sociedade futura? A realização do projeto transmoderno e pluriversal depende de uma revolução ou ele ocorrerá de forma gradual? 
A transmodernidade oferece um ferramental para superar a colonialidade e o capitalismo ou é a descrição de uma sociedade não-capitalista e sem colonialidade? Não há uma excessiva ênfase na cultura e na produção de conhecimentos em detrimento de aspectos econômicos? O simples reconhecimento da coexistência de uma multiplicidade de culturas e o fim das hierarquias entre elas, bem como entre os membros da sociedade nos levará a constituição de uma sociedade outra? Será que superados os referidos problemas, as mazelas vivenciadas no tempo presente estarão resolvidas?

Apostar na superação desses elementos, sem as mediações necessárias, não é se aproximar perigosamente de uma derivação automática — superada a colonialidade, constituiremos uma nova e melhor sociedade? Na defesa da transmodernidade, em alguma medida, a lógica do progresso, de compreensão da temporalidade como linear, unidirecional e progressiva - em direção ao novo, sempre melhor que o velho -, criticada pelo pensamento decolonial, ainda se mantém? Qual a garantia que esse novo momento da história da humanidade não será pior do que o vivenciada aqui e agora? Por fim, se a argumentação é de que a utopia decolonial é crível pois atualmente já há vestígios de sua possível realização, não há igualmente indícios de que esse projeto nunca se realizará? Se sim, como e por que continuar apostando nele? As supracitadas indagações parecem permanecer não suficientemente respondidas pelos autores e, por isso, estão abertas e servirão como horizonte para novas reflexões e para trabalhos futuros.

\section{Referências}

BALLESTRIN, Luciana Maria de Aragão. América Latina e o giro decolonial. Revista Brasileira de Ciência Política, Brasília, v. 2, p. 89-117, 2013.

BELLO, Enzo. O pensamento descolonial e o modelo de cidadania do novo constitucionalismo latino-americano. RECHTD - Revista de Estudos Constitucionais, Hermenêutica e Teoria do Direito, São Leopoldo, v. 7, p. 49-61, 2015.

BERCLAZ, Márcio Soares. Da injustiça à democracia: ensaio para uma Justiça de Libertação a partir da experiência zapatista. 2017. Tese (Doutorado em Direito) Universidade Federal do Paraná, Curitiba, 2017. 
BRAGATO, Fernanda Frizzo; CASTILHO, Natalia Martinuzzi. A importância do póscolonialismo e dos estudos descoloniais na análise do novo constitucionalismo latinoamericano. In: BELLO, Enzo; VAL, Eduardo Manuel (orgs.). O pensamento pós e descolonial no novo constitucionalismo latino-americano. Caxias do Sul: EDUCS. 2014. p. 11-25.

CASTRO-GÓMEZ, Santiago; GROSFOGUEL, Ramón. Prólogo: giro decolonial, teoría crítica y pensamiento heterárquico. In: CASTRO-GÓMEZ, Santiago; GROSFOGUEL, Ramón (coords.) El giro decolonial: reflexiones para una diversidad epistêmica más allá del capitalismo global. Bogotá: Siglo del Hombre; Universidad Central; Instituto de Estudios Sociales Contemporáneos; Pontificia Universidad Javeriana; Instituto Pensar, 2007. p. 0923.

DUSSEL, Enrique. Agenda para um diálogo inter-filosófico Sur-Sur. In: DUSSEL, Enrique. Filosofías del Sur: descolonización y transmodernidad. Ciudad de Mexico: Akal, 2015a. p. 81-102.

DUSSEL, Enrique. Europa, modernidad y eurocentrismo. In: LANDER, Edgardo (coord.). La colonialidad del saber: eurocentrismo y ciencias sociales, perspectivas latino-americanas. Buenos Aires: Clacso, 2000. p. 24-33.

DUSSEL, Enrique. Europa, modernidade e eurocentrismo. In: LANDER, Edgardo (org.) A colonialidade do saber: eurocentrismo e ciências sociais: perspectivas latino-americana. Buenos Aires: Clacso, 2005. p. 55-70.

DUSSEL, Enrique. La nueva Edad del mundo: la transmodernidad. In: DUSSEL, Enrique. Filosofías del Sur: descolonización y transmodernidad. Ciudad de México: Akal, 2015b. p. 257294 .

DUSSEL, Enrique. Materiales para una política de la liberación. Ciudad de México: Plaza y Valdés, 2007.

DUSSEL, Enrique. Meditações anti-cartesianas sobre a origem do anti-discurso filosófico da modernidade. In: SANTOS, Boaventura; MENESES, Maria Paula (orgs). Epistemologias do Sul. Coimbra: Editora Almeida. 2010. p. 283-336.

DUSSEL, Enrique. Para um diálogo Inter-filosófico Sul-Sul. Filosofazer - Revista do instituto Superior de Filosofia Berthier, Passo Fundo, n. 41, p. 11-30. 2012.

DUSSEL, Enrique. Paulo de Tarso na filosofia política atual e outros ensaios. São Paulo: Paulus, 2016. 
GOMES, David F.L.; MASSAHUD DE CARVALHO, Rayann K. Poderá o direito ser decolonial? Revista Direito e Práxis, Rio de Janeiro, 2020. Disponível em: https://www.epublicacoes.uerj.br/index.php/revistaceaju/article/view/43745/33029. Acesso em: 1 jun. 2020. DOI: 10.1590/2179-8966/2020/43745. p. 01-25.

MASSAHUD DE CARVALHO, Rayann K. Colonialidade, transmodernidade e diferença colonial: para um direito situado na periferia. 2020. Dissertação (Mestrado em Direito) Universidade Federal de Minas Gerais, Belo Horizonte, 2020.

MIGNOLO, Walter. Colonialidade: o lado mais escuro da modernidade. Rev. bras. Ci. Soc., São Paulo, v. 32. n. 94, p. 01-17, 2017 a.

MIGNOLO, Walter. Desafios decoloniais hoje. Revista Epistemologias do Sul, Foz do Iguaçu, n. 1 v. 1, p. 12-32, 2017b.

MIGNOLO, Walter. Desobediencia epistémica: retórica de la modernidad, lógica de la colonialidad y gramática de la descolonialidad. Buenos Aires: Ediciones del signo, 2010.

MIGNOLO, Walter. Histórias locais/projetos globais: colonialidade, saberes subalternos e pensamento liminar. Belo Horizonte: Editora UFMG, 2003.

MIGNOLO, Walter. La opción de-colonial: desprendimiento y apertura: un manifiesto y un caso. In: Tabula rasa, Bogotá: Universidad Colegio Mayor de Cundinamarca, n. 8, p. 243281, 2008.

MIGNOLO, Walter. La revolución teórica del zapatismo: consecuencias históricas, éticas y políticas. In: CARBALLO, Francisco; ROBLES, ROBLES, Luis Alfonso Herrera. (ed.). Habitar la frontera: sentir y pensar la descolonialidad. [S.I.]: Bellaterra, 2015b. p. 339-368.

(Antología, 1999-2014)

MIGNOLO, Walter. Pensamiento descolonial y desoccidentalización: conversación con Francisco Carballo. In: CARBALLO, Francisco; ROBLES, Luis Alfonso Herrera. (ed.). Habitar la frontera: sentir y pensar la descolonialidad. [S.I.]: Bellaterra. 2015c. p. 81-110. (Antología, 1999-2014)

PAZELLO, Ricardo Prestes. Direito insurgente e movimentos populares: o giro descolonial do poder e a crítica marxista ao direito. 2014. 545 f. Tese (Doutorado em Direito) - Programa de Pós-Graduação em Direito, Setor de Ciências Jurídicas, da Universidade Federal do Paraná, Curitiba, 2014.

QUIJANO, Aníbal. Colonialidad del poder y clasificación social. Journal of world-systems research, Pittsburgh, v. 11, n. 2, p. 342-386, 2000. 
QUIJANO, Aníbal. Colonialidade do poder e classificação social. In: SANTOS, Boaventura de Sousa; MENESES, Maria Paula (orgs.). Epistemologias do Sul. São Paulo: Cortez, 2010. p. 73-118.

QUIJANO, Aníbal. Colonialidad del poder y des/colonialidad del poder. CONGRESO DE LA ASOCIACIÓN LATINOAMERICANA DE SOCIOLOGÍA, 27., 2009, Buenos Aires. Anales [...]. Buenos Aires: [s.n.], 2009a. p. 1-15.

QUIJANO, Aníbal. Otro horizonte de sentido histórico. América Latina en Movimiento, [S.I.], n. 441, p. 02-32, 2009b.

Recebido em: 11/06/2020 Aprovado em: 29/12/2020

Universidade do Estado de Santa Catarina - UDESC Centro de Ciências Humanas e da Educação - FAED

Volume 21 - Número 47 - Ano 2020 revistapercursos@gmail.com 